\title{
The Postembryonic Development of the Ocellar System of Triatoma infestans Klug (Heteroptera: Reduviidae)
}

\author{
Teresita C Insausti, Claudio R Lazzari ${ }^{+}$
}

\begin{abstract}
Departamento de Biología, Facultad de Ciencias Exactas y Naturales, Universidad de Buenos Aires, Ciudad Universitaria, (1428) Buenos Aires, Argentina
\end{abstract}

Simple eyes or ocelli coexist with compound eyes in many adult insects. The change in the morphology of the ocelli along the five larval instars of Triatoma infestans was studied by light and scanning electron microscopy. Our analysis showed that the development of the ocelli of these bugs occurs gradually along the larval life. The photoreceptor layer is present from the second-instar onwards. The cornea appears first at the imaginal stage and grows up to the 18-20th day after the last ecdysis, associated to an increase in the retinal mass. Findings are discussed in a comparative fashion and in relation to the functionality of the ocellar system in $\mathrm{T}$. infestans.

Key words: Triatoma infestans - ocelli - development - Chagas disease

The possession of dorsal ocelli is a typical characteristic of adult insects, but little attention has been paid to ocellar development along the larval life. In holometabolous insects ocelli are said to be differentiated from the compound eye/antennal/ocellar imaginal disc (Caesar 1913), whereas in hemimetabolous insects they are variously reported as "present" or as being "formed" or "perfected" in the larval stages. External observations suggest that there may be different rates of development among hemimetabolous forms. In some cases, like locusts and mayflies, there are clearly visible ocelli with obvious lenses even in early instars, whilst stone-flies and dragon-flies, for example, show only pigmented spots or faint traces of the tapetal layer beneath the cuticle until just prior to adult emergence (Goodman 1981). Locusts are the only insects in which ocellar development has been carefully documented from embryonic to imaginal stages (Mobbs 1976, 1979).

Triatoma infestans adults have two ocelli located behind the compound eyes, looking

This work received financial support from the Universidad de Buenos Aires, CONICET/Argentina, and the WHO/UNDP/World Bank Special Programme for Research and Training in Tropical Diseases.

${ }^{+}$Corresponding author. Fax: +54- 11- 4576.3384/4544 7893. E-mail: lazzari@bg.fcen.uba.ar

Received 20 September 1999

Accepted 19 June 2000 dorsolaterally and frontally. The ocelli are well developed with prominent spherical lenses (about $455 \mu \mathrm{m}$ in diameter) overlying the photoreceptor layer (Insausti et al. 1999). In this species they are involved in phototactic response (Lazzari et al. 1998). In these bugs, ocelli do not become externally evident during larval instars and, as an unusual characteristic among insects, completion of their development is attained during the imaginal life (Insausti 1997).

The high degree of complexity of $T$. infestans ocelli and its role in guiding behaviour brought us to analyse its origin and development. The aim of the present paper is to describe morphological aspects of the ocellus postembryonic development of this haematophagous bug.

\section{MATERIALS AND METHODS}

T. infestans from our laboratory colony were reared at $28^{\circ} \mathrm{C}$ and fed on heparinized bovine blood by means of an artificial feeder (Núñez \& Lazzari 1990). Adults as well as first to fifth larval instars were used in the present study.

Light microscopy was performed on bugs' heads fixed in a mixture of glutaraldehyde $2.5 \%$ and paraformaldehyde $2 \%$ in phosphate buffer $(\mathrm{pH}$ 7.3) and postfixed with $1 \%$ osmium tetroxide. After dehydration, the heads were embedded in Durcupan, cut in $5 \mu \mathrm{m}$ thick sections on glass knives, and stained with methylene blue.

Scanning electron microscopy was accomplished on fresh or fixed heads, using an Environmental Scanning Electron Microscope (ESEM Philips Electro Scan, Mod. 2010). This equipment does not require sample metal covering, allowing the observation of intact biological material. 


\section{RESULTS}

Until adult emergence there is no external indication of the existence of a simple eye in $T$. infestans. External inspection of fifth instar larva head does not reveal corneal lenses. In both early emerged or ready to moult larvae the cuticle of the region where adult ocelli will appear is similar to that of the rest of the head. However, a small protrusion covered by mechanosensory sensilla chaetica can be distinguished on the place where the corneal lens will be located after the imaginal ecdysis (Fig. 1).
Transversal sections of heads of recently hatched first-instar T. infestans larvae show in the ocellar area some pigmentary cells with small prolongations towards the brain. This would constitute the first rudiment of the adult ocellus (Fig. 2A).

In second-instar larvae, this rudimentary ocellus reaches about 15-20 $\mu \mathrm{m}$ in diameter and is constituted by a few retinular cells filled with darkbrown pigment (Fig. 2B). The same pattern was found in larvae of third- and fourth-instars (Figs $2 \mathrm{C}, \mathrm{D})$. The size of the retina was observed to increase along development, reaching about $25 \mu \mathrm{m}$ in the third- and ca. $30 \mu \mathrm{m}$ in the fourth-instar. In
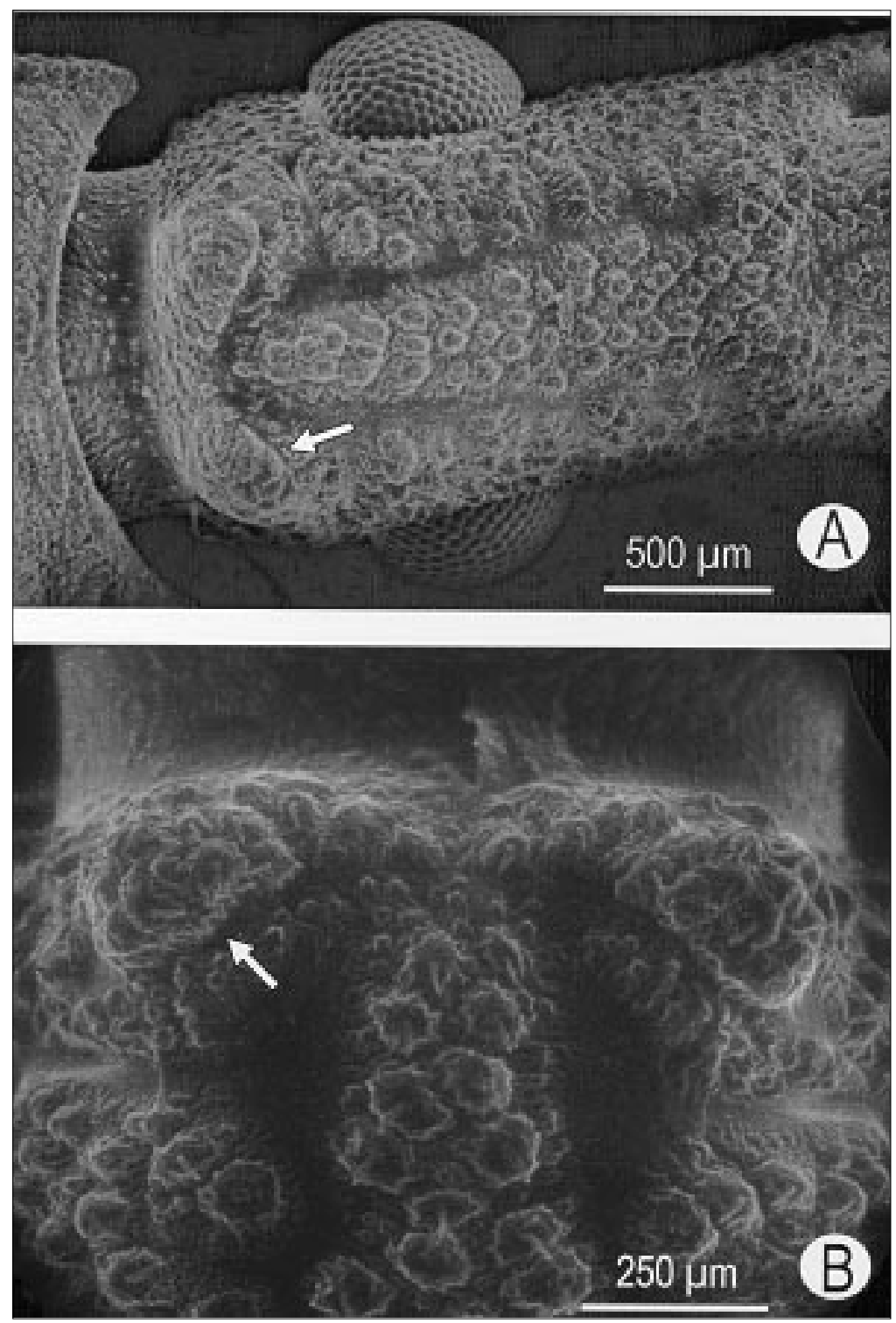

Fig. 1 - A: scanning electron micrograph view of a Triatoma infestans fifth instar larva head. The arrow shows the region where the adult ocelli will appear; in detail in B (arrow). 
Mem Inst Oswaldo Cruz, Rio de Janeiro, Vol. 95(6), Nov./Dec. 2000

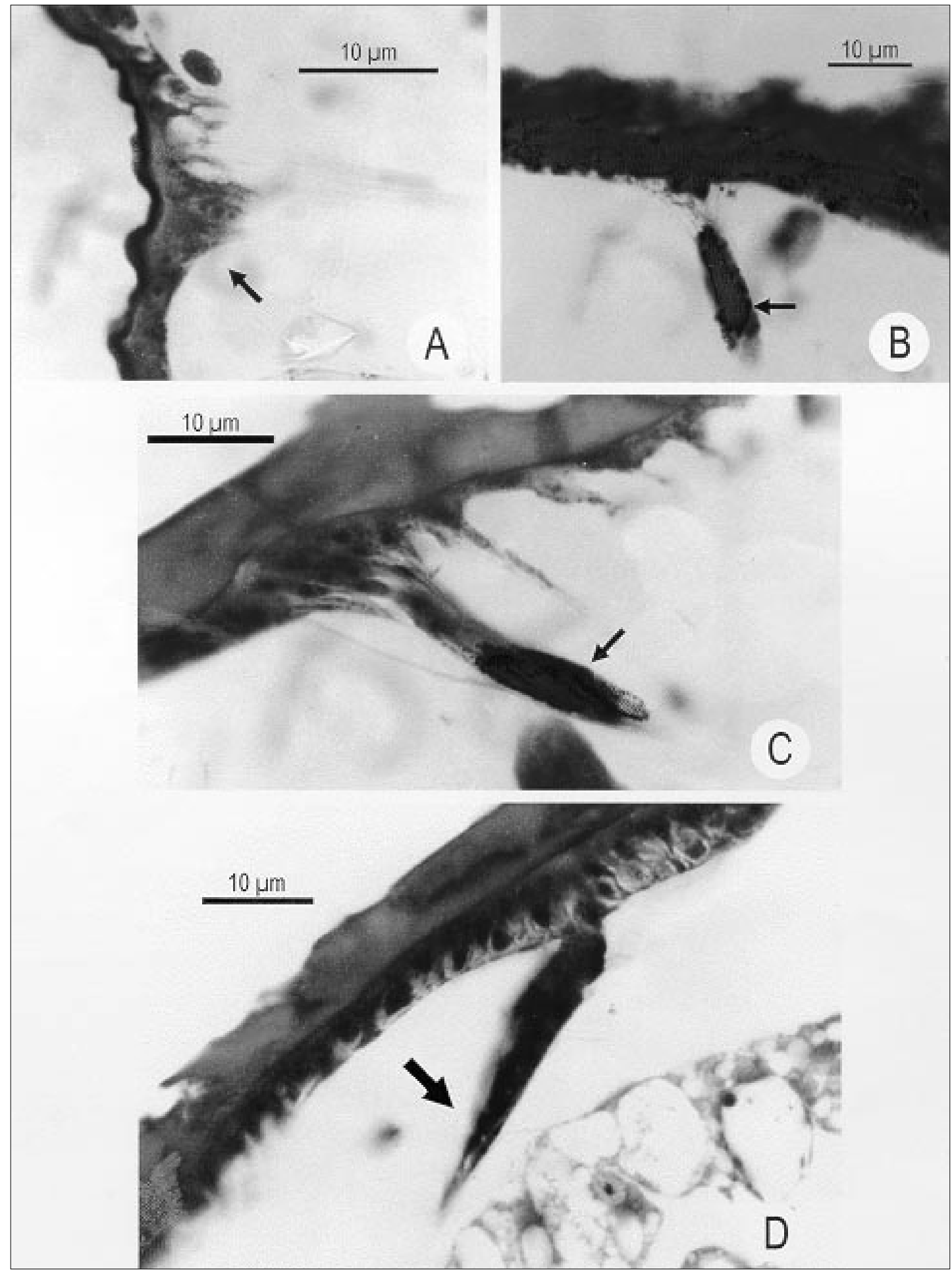

Fig. 2: transversal cross sections of heads of the first four larval stages of Triatoma infestans. Arrows indicate ocellar rudiments. A: first-instar larva; B: second-instar larva; C: third-instar larva; D: fourth-instar larva 
contrast to adult ocellus (Insausti 1997), no apodeme was observed to be present around the ocellar cup.

In fifth-instar larva, the ocellar rudiment reaches about $35 \mu \mathrm{m}$ in diameter, being represented by some retinular cells filled with dark-brown pigment, surrounded by pigmentary cells of redbrownish pigment (Fig. 3B). At this instar, a small apodeme forming the ocellar cup is recognized (Fig. 3A).

\section{DISCUSSION}

T. infestans ocellus postembryonary development occurs in a gradual fashion along the larval life. The photoreceptor layer, as well as the ocellar nerve could be detected from the second instar on.

The corneal lens, on the contrary, does not complete its development up to the 18th-20th day after the imaginal ecdysis. External analysis of the early emerged adults heads revealed a conspicuous cornea that exhibits a narrow curved "pupil", having
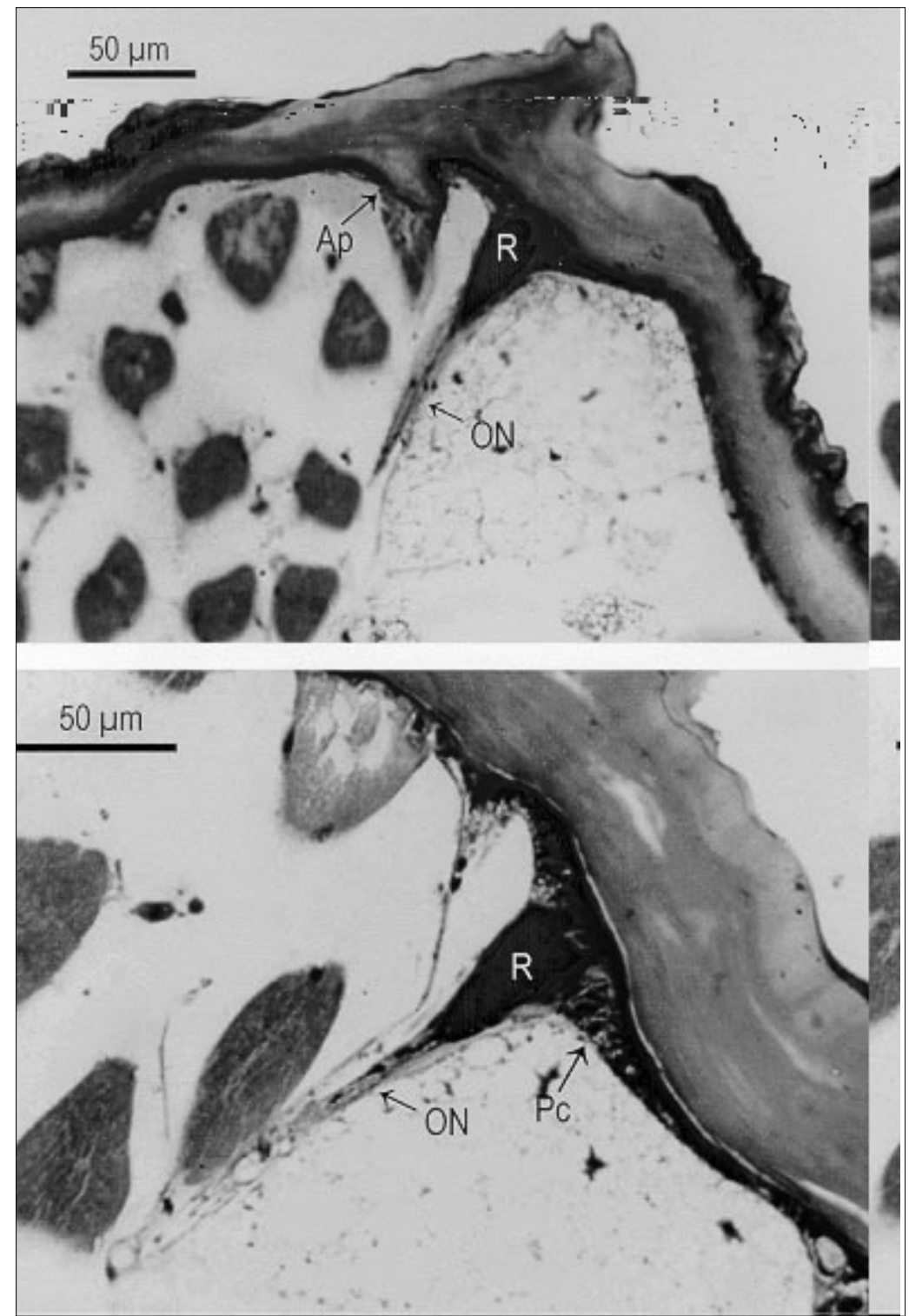

Fig. 3: transversal cross sections of the head of a Triatoma infestans fifth-instar larva. Ap: apodeme; Pc: pigmentary cells; ON: ocellar nerve; R: retina 
its major axis parallel to the main axis of the head. Morphological analysis revealed that recently emerged imagos lack a full-developed ocellar cornea. Only the region corresponding to the "pupil" appears as a thickened lens. The retina is also restricted to this zone, whereas pigmentary cells form the "iris" that delimitates the "pupil". Adults older than 20 days possess a very thick and almost spherical cornea of about $455 \mu \mathrm{m}$ in diameter. In this insect a layer of photoreceptors fills the whole ocellar cup and pigmentary cells are restricted to a peripheral ring (Insausti \& Lazzari 2000). The development of the adult ocellus and the growth of the "pupil" have been proposed as a tools for age determinations of triatomines (Corchs et al. 1999).

Certain variability in the rate of growth of the ocelli has been observed among hemimetabolic insects. The locust ocelli development, for example, is completed during the embryonic stage. Only an increase in ocelli size is observed during larval growth (Mobbs 1976, 1979). In Ephemeroptera the ocellus with evident lens is clearly seen since the first larval instar. By contrast, stoneflies and dragonflies only exhibit pigmentary spots or weak signs of the tapetal layer below the cuticle, immediately before adult emergence. In the cockroach Periplaneta americana tapetal cells can be seen through the cuticle after egg hatching, and a gradual growth can be followed along the larval life (Goodman 1981). Unless the differentiation of the ocellar rudiments of the three main cell layers (i.e., corneagen, photoreceptive and support cells) has been described in several insects (Redikorzew 1900, Link 1909, Caesar 1913), very few details about the innervation of the ocelli and the growth of peripheral neuropile are available. In particular, the question about when the ocellus becomes functional remains opened in most cases.

\section{ACKNOWLEDGMENTS}

To the staff members of the laboratory for many fruitful discussions.

\section{REFERENCES}

Caesar CJ 1913. Die Stirnaugen der Ameisen. Zool Jb (Anat) 35: 161-242.

Corchs MJ, Insausti TC, Lorenzo MG Diotaiuti L, Lazzari CR 1999. A possible age indicator for adult triatomines. Resumos XVI Congresso Brasileiro de Parasitología, 83.

Goodman LJ 1981. Organisation and physiology of the insect dorsal ocellar system. In H Autrum, Handbook of Sensory Physiology, Vol VII/6C, Springer-Verlag, Berlin, Heidelberg \& New York, p. 201-286.

Insausti TC 1997. Estudio del Sistema Ocelar de la Vinchuca Triatoma infestans (Klug, 1834) (Heteroptera: Reduviidae), PhD Thesis, University of Buenos Aires, Argentina, 257 pp.

Insausti TC, Lazzari CR 2000. An ocellar "pupil" that does not change with light intensity, but with the insect age in Triatoma infestans. Mem Inst Oswaldo Cruz 95: in press.

Insausti TC, Lazzari CR, Campanucci VA 1999. Neurobiology of behaviour. A: Morphology of the nervous system and sense organs. In RU Carcavallo, I Galindez Girón, J Jurberg, H Lent (eds), Atlas of Chagas Disease Vectors in the Americas, Vol. III/23A, Editora Fiocruz, Rio de Janeiro, p. 1017-1051.

Lazzari CR, Reisenman CE, Insausti TC 1998. The role of the ocelli in the phototactic response of Triatoma infestans (Heteroptera: Reduviidae). J Insect Physiol 44: 1159-1162.

Link E 1909. Über die Stirnaugen der hemimetabolen Insekten. Zool Jb (Abt Anat Ontog) 27: 281-376.

Mobbs PG 1976. Development of the locust ocellus. Nature 264: 269-271.

Mobbs PG 1979. Development of the dorsal ocelli of the desert locust Schistocerca gregaria Forsk (Orthoptera: Acrididae). Int J Insect Morphol Embryol 8: 237-255.

Núñez JA, Lazzari CR 1990. Rearing of Triatoma infestans Klug (Het., Reduviidae) in the absence of a live host. I. Some factors affecting the artificial feeding. J Applied Entomol 109: 87-92.

Redikorzew W 1900. Untersuchungen über den Bau der Ocellen der Insekten. Z wiss Zool 68: 581625 . 
882 Development of the Triatoma Ocellus - TC Insausti, CR Lazzari 